\title{
Lower Limb Motor Coordination of Stroke Survivors, Based Upon Their Levels of Motor Recovery and Ages
}

Kenia Kiefer Parreiras de Menezes*, Aline Alvim Scianni, Iza Faria-Fortini, Patrick Roberto Avelino, Christina DCM Faria and Luci Fuscaldi Teixeira-Salmela Department of Physical Therapy, Federal University of Minas Gerais, Belo Horizonte, Minas Gerais, Brazil.

*Corresponding author: Kenia Kiefer Parreiras de Menezes, Department of Physical Therapy, Universidade Federal de Minas Gerais, Avenida Antônio Carlos, 6627, Campus Pampulha, 31270-901 Belo Horizonte, Minas Gerais, Brasil, Tel: 55-31-3409-7403; Fax: 55-31-3409-8403; E-mail: keniakiefer@yahoo.com.br

Received date: Nov 23, 2015; Accepted date: Dec 09, 2015; Published date: Dec 16, 2015

Copyright: @ 2015 de Menezes KKP, et al. This is an open-access article distributed under the terms of the Creative Commons Attribution License, which permits unrestricted use, distribution, and reproduction in any medium, provided the original author and source are credited.

\begin{abstract}
Objective: To describe the motor coordination (MC) of the paretic lower limb of stroke survivors based upon their levels of motor recovery and ages and to compare their LEMOCOT scores with those predicted for healthy subjects of similar ages and genders.

Methods: MC was assessed by the Lower Extremity Motor Coordination Test (LEMOCOT). The participants were divided, according to their ages and levels of motor recovery, based upon the Fugl-Meyer (FM) lower limb section scores (mild impairments: FM $\geq 23$ and severe impairments: FM <23). To compare the LEMOCOT scores of the paretic lower limb with those predicted for healthy subjects, the predicted equations for the non-dominant lower limb of healthy subjects of similar ages and genders were employed. Results/Discussion: Age did not influence the LEMOCOT scores, but the subjects with severe motor impairments always showed lower scores, when compared to those with mild impairments, regardless of their ages. The subjects with mild motor impairments reached $75 \%$, while those with severe motor impairments reached only $20 \%$ of the predicted scores for healthy subjects.
\end{abstract}

Conclusions: The findings suggested that the subjects with mild motor impairments had better MC, than those with severe impairments, regardless of their ages. Furthermore, the subjects with mild motor impairments reached $75 \%$, whereas those with severe impairments reached only $20 \%$ of the predicted scores for healthy subjects

Keywords: Stroke, Lower extremity, Motor coordination

\section{Introduction}

Loss of strength and dexterity following upper motor neuron damage, e.g., a stroke, mostly contribute to disabilities [1]. Motor coordination (MC) or dexterity refers to the ability to perform a motor task in an accurate, rapid, and controlled manner in order to achieve a given environmental demand [2,3]. Adequate $\mathrm{MC}$ of the lower limbs is important for the performance of activities of daily living, since they are involved in many everyday motor activities such as walking, running, ascending/descending stairs, standing from a chair, being the effective performance of these tasks critical for an independent life [4,5]. Furthermore, adequate lower limb MC significantly contributes to functionality of stroke individuals, being its loss the major contributor to disability in this population [6].

Usually, MC is tested under conditions, where some temporal and spatial accuracies are required [2]. The Lower Extremity Motor Coordination Test (LEMOCOT), developed to quantitatively assess lower limb MC [5], is a simple test with adequate psychometric properties for the assessment of MC in stroke subjects [7]. Furthermore, has the ability to detect changes in $\mathrm{MC}$ after stroke [8] and lower back pain [9], and it is a strong predictor of social participation after stroke rehabilitation [10]. The LEMOCOT reference values were established for healthy individuals, based on their ages and genders, and these factors together explained 44 to $48 \%$ of the variance in the LEMOCOT scores, when younger age and male sex were associated with better coordination [11]. However, for stroke subjects, other factors may be more important. Menezes et al. [12] found that levels of motor impairments, as assessed by the Fugl-Meyer (FM) lower limb section scores and age together explained $49 \%$ of the variance in the LEMOCOT scores [12]. Thus, is necessary to investigate the MC performance of stroke survivors considering these predictor variables (motor recovery and age), such as was made to healthy subjects [11], considering the predictors age and gender.

Thus, considering significant impairments in MC after stroke and the previous reported predictors of the LEMOCOT scores for this population, the aim of the present study was to describe the motor coordination (MC) of the paretic lower limb of stroke survivors, based upon their levels of motor impairments and ages and to compare their LEMOCOT scores with those predicted healthy subjects of similar ages and genders.

\section{Methods}

\section{Participants}

Community-dwelling people with stroke living in the city of Belo Horizonte, Brazil, were recruited if they were $\geq 20$ years of age and at least six months after the onset of the stroke; had weakness and/or increased tonus of the paretic knee extensor and/or ankle plantar flexor muscles, as determined by $15 \%$ strength differences between the paretic and non-paretic limbs [13] and/or scores different from zero on the Modified Ashworth Scale (MAS) [14]; and had no cognitive impairments, as determined by the following education-adjusted cutoff scores on the Mini-mental state examination: 18/19 for the 
Citation: de Menezes KKP, Scianni AA, Faria-Fortini I, Avelino PR, Faria CDCM, et al. (2015) Lower Limb Motor Coordination of Stroke Survivors, Based Upon Their Levels of Motor Recovery and Ages. J Neurol Neurophysiol 6: 338. doi:10.4172/2155-9562.1000338

Page 2 of 3

individuals with illiteracy and $24 / 25$ for those with basic education [15].

\section{Procedures}

Before data collection, eligible participants were informed about the objectives of the study and were requested do sign a written consent agreeing to participate of the study, based upon previous approval from the University ethical review board.

All data were collected by well-trained physical therapists. Initially, demographic and clinical data were obtained by interviews, including the subjects' ages and levels of motor impairments, which were determined by the Fugl-Meyer (FM) lower limb-section scores. The FM was selected because is the best predictor of the LEMOCOT scores in stroke survivors. The age was selected because also is a predictor of the LEMOCOT scores in stroke and healthy subjects, besides being an easy measure to obtain.

The FM is a valid and reliable scale used to assess motor recovery and is one of the most widely used instruments for clinical assessments [16]. A three-point ordinal scale is applied for each item, where "zero" is given to a task that cannot be carried-out, "one" when the task is partially performed, and "two" for tasks that can be completely performed [17].

To perform the LEMOCOT with their paretic lower limbs, the subjects seated on an adjustable chair with their feet resting flat on a thin rigid foam, heels on the proximal target, and knees at $90^{\circ}$ of flexion [5]. Then, after a familiarization trial, they were instructed to alternately touch the proximal and distal targets placed $30 \mathrm{~cm}$ apart with their big toe, for 20 seconds. The number of touched targets was counted and registered for analyses [5].

\section{Statistical analyses}

Descriptive statistics and tests for normality were calculated. The subjects were divided, according to their levels of motor impairments and ages. The participants were divided into two sub-groups, according to their levels of motor impairments (mild: $F M \geq 23$ and severe: $\mathrm{FM}<23$ ). To compare the LEMOCOT scores of the paretic limb of stroke subjects with those predicted for healthy subjects, the age- and gender-matched predictive equations for the non-dominant lower limb of healthy subjects reported by Pinheiro et al. [11], were employed. All analyses were performed with the SPSS (version 17.0) with a significance level of $5 \%$.

\section{Results}

A total of 102 subjects (59 with mild and 43 with severe motor impairments) , 61 men, with a mean age of $60.2 \pm 10.4$ years, ranging from 40 to 79 years and a mean time since the onset of the stroke of $71.2 \pm 68.1$ months, ranging from three to 380 months, were assessed. Their descriptive data are summarized in Table 1.

The mean LEMOCOT scores for the paretic lower limb, based upon the subjects' levels of motor impairments and ages are given in Table 2. Age did not influence the LEMOCOT scores, but the subjects with severe motor impairments always showed lower scores, when compared to those with mild impairments, regardless of their ages. The mean predicted LEMOCOT score for healthy subjects of similar ages and genders would be $30.7 \pm 3.8$. However, the subjects with mild motor impairments reached $75 \%$, whereas those with severe motor impairments reached $20 \%$ of the predicted scores for healthy subjects.

\begin{tabular}{|c|c|c|}
\hline \multicolumn{2}{|l|}{ Variable } & $n=102$ \\
\hline \multicolumn{2}{|l|}{ Gender, men, n (\%) } & $61(59.8)$ \\
\hline \multicolumn{2}{|l|}{ Age (years), mean \pm SD (range) } & $60.2 \pm 10.4(40-79)$ \\
\hline \multicolumn{2}{|l|}{ Time since stroke (months), mean \pm SD (range) } & $71.2 \pm 68.1(3-380)$ \\
\hline $\begin{array}{l}\text { LEMOCOT scores of the paretic lower limb, } \\
\text { taps/sec, mean } \pm \text { SD (range) } \\
\text { Lower limb motor recovery, Fugl-Meyer scale } \\
\text { classification, } n(\%)\end{array}$ & $\begin{array}{l}\text { mild } \\
\text { severe }\end{array}$ & $\begin{array}{l}15.7 \pm 11.7(0-46) \\
59(57.8) \\
43(42.2)\end{array}$ \\
\hline
\end{tabular}

Table 1: Participants' characteristics $\left({ }^{*} \mathrm{SD}=\right.$ Standard deviation)

\begin{tabular}{|c|c|c|c|}
\hline $\begin{array}{ll}\begin{array}{l}\text { Age } \\
\text { (years) }\end{array} & \text { group } \\
\end{array}$ & $\mathbf{n}$ & $\begin{array}{l}\text { Motor } \\
\text { recovery }\end{array}$ & LEMOCOT scores \\
\hline $40-49$ & $\begin{array}{l}12 \\
8\end{array}$ & $\begin{array}{l}\text { mild } \\
\text { severe }\end{array}$ & $\begin{array}{l}22.5(8.3-33.3) \\
3.9(0-21.0)\end{array}$ \\
\hline $50-59$ & $\begin{array}{l}15 \\
13\end{array}$ & $\begin{array}{l}\text { mild } \\
\text { severe }\end{array}$ & $\begin{array}{l}25.5(10.0-43.0) \\
9.1(0-18.7)\end{array}$ \\
\hline $60-69$ & $\begin{array}{l}18 \\
12\end{array}$ & $\begin{array}{l}\text { mild } \\
\text { severe }\end{array}$ & $\begin{array}{l}20.4(6.0-34.0) \\
4.3(0-13.3)\end{array}$ \\
\hline $70-79$ & $\begin{array}{l}14 \\
10\end{array}$ & $\begin{array}{l}\text { mild } \\
\text { severe }\end{array}$ & $\begin{array}{l}23.5(11.7-46.0) \\
5.4(0-18.0)\end{array}$ \\
\hline Total & $\begin{array}{l}59 \\
43\end{array}$ & $\begin{array}{l}\text { mild } \\
\text { severe }\end{array}$ & $\begin{array}{l}23.0(6.0-46.0) \\
5.7(0-21.0)\end{array}$ \\
\hline
\end{tabular}

Table 2: Mean scores and range (min-max) of the lower extremity motor coordination test of the paretic lower limb of stroke survivors, based upon their ages and levels of motor recovery

\section{Discussion}

This study aimed to describe the motor coordination (MC) of the paretic lower limb of stroke survivors, based upon their levels of motor impairments and ages and to compare their LEMOCOT scores with those predicted for healthy subjects of similar ages and genders.

The mean LEMOCOT scores of the subjects with severe motor impairments were considerably lower than those with mild impairments. Furthermore, the subjects with mild impairments reached $75 \%$ of the predicted values for healthy subjects, whereas those with severe impairments reached only $20 \%$ of the expected values. Although Menezes et al. [7] reported that the mean scores of the paretic lower limb were approximately half of those predicted for the non-dominant limb of healthy individuals, when the sample was stratified according the levels of motor recovery, i.e. severity of motor impairments, these percentage values changed. In the present study, the stroke subjects with mild impairments achieved more than $50 \%$ of the predicted scores for the healthy subjects, while the stroke subjects with severe impairments achieved less than 50\%. These findings corroborated those of Menezes et al. [12], who found that levels of motor recovery was the main predictor and explained $46 \%$ of the variance in the LEMOCOT scores. Thus, variables assessed by the FM lower limb motor section scores, such as motor synergy and range of motion, are important to execute the LEMOCOT. Furthermore, other studies also found that the motor recovery was significantly associated with other impairments after stroke $[18,19]$. 
Citation: de Menezes KKP, Scianni AA, Faria-Fortini I, Avelino PR, Faria CDCM, et al. (2015) Lower Limb Motor Coordination of Stroke Survivors, Based Upon Their Levels of Motor Recovery and Ages. J Neurol Neurophysiol 6: 338. doi:10.4172/2155-9562.1000338

Page 3 of 3

Although age also was shown to be a predictor of the LEMOCOT scores [12], in the present study, younger subjects did not reach higher LEMOCOT scores. These results can be explained maybe because age explained only $3 \%$ of the variance in the LEMOCOT scores [12]. Other studies also reported that the age does not affect the performance of stroke survivors $[20,21]$.

\section{Study limitations}

Although the sample was broad and drawn from various settings, it was not randomly selected and may not, therefore, be fully representative of the stroke population. Furthermore, the subjects' ages in the present study, ranged from 40 to 79 years. Although the incidence of stroke in subjects under 40 years is increasing over the last years [22], there were only six individuals under 40 years of age, number not sufficient to be included in the analyses. Finally, the external validity of the present results obtained here should be further confirmed and investigated in other populations. For instance, the subjects of the present study were in the subacutet chronic phase of stroke and had enough time to recover. However, subjects at acute stages of recovery could demonstrate different results.

\section{Conclusion}

The findings suggested that the subjects with mild motor impairments had better MC of the paretic lower limb, than those with severe impairments, regardless of their ages. Furthermore, the subjects with mild motor impairments reached $75 \%$, whereas those with severe impairments reached only $20 \%$ of the predicted scores for healthy subjects.

\section{References}

1. Roger VL, Go AS, Lloyd-Jones DM, Benjamin EJ, Berry JD, et al. (2012) Heart diseases and stroke statistic update: a report from the American Heart Association. Circulation 125: e2-220.

2. Bernstein NA (1996) Dexterity and its development. (1stedn), Mahwah: Lawrence Erlbaum Associates, Mahwah, New Jersey.

3. Bourbonnais D, Vanden Noven S, Pelletier R (1992) Incoordination in patients with hemiparesis. Can J Public Health 83 Suppl 2: S58-63.

4. Carr JH, Shepherd RB (2010) Neurological rehabilitation: optimizing motor performance. (2ndedn), Oxford: Churchill Livingstone.

5. Desrosiers J, Rochette A, Corriveau H (2005) Validation of a new lowerextremity motor coordination test. Arch Phys Med Rehabil 86: 993-998.

6. Ada L, Canning C (2005) Changing the way we view the contribution of motor impairments to physical disability after stroke. In: Refshauge K, Ada L, Ellis E, editors. Science-based rehabilitation: Theories into practice, Elsevier, Sydney. 87-106.

7. de Menezes KK, Scianni AA, Faria-Fortini I, Avelino PR, Faria CD, et al. (2015) Measurement properties of the lower extremity motor coordination test in individuals with stroke. J Rehabil Med 47: 502-507.
8. Desrosiers J, Malouin F, Richards C, Bourbonnais D, Rochette A, et al. (2003) Comparison of changes in upper and lower extremity impairments and disabilities after stroke. Int J Rehabil Res 26: 109-116.

9. Yildirim Y, Bilge K, Erbayraktar S, Sayhan S (2008) Assessment of lower extremity motor coordination in operated patients. J Musculoskelet Res 11: $107-115$

10. Desrosiers J, Noreau L, Rochette A, Bravo G, Boutin C (2002) Predictors of handicap situations following post-stroke rehabilitation. Disabil Rehabil 24: 774-785.

11. Pinheiro MB, Scianni AA, Ada L, Faria CD, Teixeira-Salmela LF (2014) Reference values and psychometric properties of the lower extremity motor coordination test. Arch Phys Med Rehabil 95: 1490-1497.

12. Menezes KKP, Scianni AA, Faria-Fortini I, Avelino PR, Carvalho AC, et al. (2015) Potential predictors of lower extremity impairments in motor coordination of stroke survivors. Eur J Phys Rehabil Med.

13. Faria CDCM, Teixeira-Salmela LF, Nadeau S (2013) Predicting levels of basic functional mobility, as assessed by the Timed "Up and Go" test, for individuals with stroke: discriminant analyses. Disabil Rehabil 35: 146-152.

14. Gregson JM, Leathley M, Moore AP, Sharma AK, Smith TL, et al. (1999) Reliability of the Tone Assessment Scale and the modified Ashworth scale as clinical tools for assessing poststroke spasticity. Arch Phys Med Rehabil 80: 1013-1016.

15. Bertolucci P, Brucki S, Campacci S, Juliano Y (1994) The Mini-Mental state examination in an outpatient population: influence of literacy. Arq Neuropsiquiatr 52: 1-7.

16. Kim H, Her J, Ko J, Park D, Woo J (2012) Reliability, concurrent validity, and responsiveness of the Fugl-Meyer Assessment (FMA) for hemiplegic patients. J Phys Ther Sci 24: 893-899.

17. Fugl-Meyer AR, Jääskö L, Leyman I, Olsson S, Steglind S (1975) The poststroke hemiplegic patient. 1. a method for evaluation of physical performance. Scand J Rehabil Med 7: 13-31.

18. Gebruers N, Truijen S, Engelborghs S, De Deyn PP (2014) Prediction of upper limb recovery, general disability, and rehabilitation status by activity measurements assessed by accelerometers or the Fugl-Meyer score in acute stroke. Am J Phys Med Rehabil 93: 245-252.

19. Desrosiers J, Malouin F, Bourbonnais D, Richards CL, Rochette A, et al. (2003) Arm and leg impairments and disabilities after stroke rehabilitation: relation to handicap. Clin Rehabil 17: 666-673.

20. Suzuki K, Imada G, Iwaya T, Handa T, Kurogo H (1999) Determinants and predictors of the maximum walking speed during computer-assisted gait training in hemiparetic stroke patients. Arch Phys Med Rehabil 80: 179-182.

21. Patterson SL, Forrester LW, Rodgers MM, Ryan AS, Ivey FM, et al. (2007) Determinants of walking function after stroke: differences by deficit severity. Arch Phys Med Rehabil 88: 115-119.

22. Kissela BM, Khoury JC, Alwell K, Moomaw CJ, Woo D, et al. (2012) Age at stroke: temporal trends in stroke incidence in a large, biracial population. Neurology 79: 1781-1787. 